\title{
Dependencia geométrica en la composición del vitral del Espíritu Santo en la catedra de San José de Cúcuta.
}

\section{Geometric dependence in the composition of the stained glass window of the Holy Spirit in the Cathedral of San José de Cúcuta.}

\author{
Mawency Vergel Ortega ${ }^{1}$ \\ Yannette Díaz Umaña \\ Julio Alfredo Delgado Rojas ${ }^{3}$ \\ Universidad Francisco de Paula Santander.
}

\section{RESUMEN}

Este artículo se deriva de la investigación en arquitectura sagrada desarrollada por los programas de maestría en educación matemática y arquitectura de la UFPS, cuyo

1 Doctora en Educación. Postdoctora en Imaginarios y representaciones sociales. Docente y Directora del Departamento de Matemáticas y Estadística. Filiación: Universidad Francisco de Paula Santander. Correo electrónico: mawency@ufps.edu.co. Orcid: https://orcid.org/0000-00018285-2968

2 Magister en Gestión Urbana, Arquitecta, docente y directora del Departamento de Arquitectura, diseño y Urbanismo. Filiación: Universidad Francisco de Paula Santander. Correo electrónico: yannettedu@ufps.edu.co Orcid: https://orcid.org/0000-0003-4582-1593

3 Magister en Educación Matemática, Arquitecto, Docente. Filiación: Universidad Francisco de Paula Santander. Correo electrónico: julioalfredo@ufps.edu.co Orcid: https://orcid.org/0000-0001-6944-832X objetivo, para este caso, es la apreciación patrimonial de este elemento lumínico con gran valor simbólico y artístico. La metodología llevada a cabo para esta investigación, se inicia con el levantamiento gráfico de los elementos a estudiar, su localización y la incidencia solar. Al mismo tiempo, se hace necesaria la recopilación de la documentación para establecer los lazos históricos, tipológicos, iconológicos y geométricos. De esta manera la observación, análisis e interpretación, permitirá distinguir tamaño, forma, iconografía y geometría, para el reconocimiento patrimonial del vitral del Espíritu Santo de $3,25 \mathrm{~m}$ de diámetro, ubicado en el ábside de la Catedral de San José de Cúcuta. 
Palabras clave: arquitectura sagrada, arte vitral, geometría e iconografía.

\section{ABSTRACT}

This article is derived from the research in sacred architecture developed by the mathematics and architecture programs of the UFPS, whose objective, for this case, is the patrimonial appreciation of this light element with great symbolic and artistic value. The methodology carried out for this research begins with the graphic survey of the elements to be studied, their location and the solar incidence. At the same time, the compilation of documentation is necessary to establish historical, typological, iconological and geometric ties. In this way, the observation, analysis and interpretation lost the distinction of size, shape, iconography and geometry, for the patrimonial recognition of the $3.25 \mathrm{~m}$ diameter stained glass window of the Holy Spirit, located on the side of the Cathedral of San José de Cúcuta.Keywords: sacred architecture, stained glass art, geometry and iconography.

\section{KEYWORDS:}

sacred architecture, stained glass art, geometry and iconography.

\section{INTRODUCCIÓN}

El arte vitral cuyos orígenes se distinguen en el románico cobraron gran importancia en el gótico, dotando al espacio de luz, color y calidez espacial, ubicándolos entre lo eminentemente arquitectónico y lo ornamental. El arte vitral se fundamenta en el concepto de la luz como elemento primordial (Vergel, Delgado \& Díaz 2020), por su parte Campo (1998), la considera componente esencial, es materia y material, cuantificable y calificable. De ahí que la ubicación de este elemento arquitectónico con referencia al contacto con la luz, determina la apreciación simbólica, fenomenológica, cromática y geométrica, por parte de los fieles en el lugar más visible de la catedral desarrollada en una planimetría en forma de cruz latina (Díaz, Delgado \& Vergel 2021).

Para este estudio del vitral del Espíritu Santo ubicado en el ábside de la catedral de San Jose de Cúcuta, se aborda el modelo propuesto por Panofsky (1970), quien propone para la lectura de imágenes: la descripción de los elementos compositivos de la imagen denominada Iconográfico, en correspondencia de estas imágenes con las fuentes literarias y la categoría alcanzada mediante el estudio geométrico, de tal forma que se indique sus características particulares. Así la metodología llevada a cabo para esta investigación, tuvo como punto de partida el levantamiento gráfico de todos y cada uno de los elementos a estudiar, su localización y la incidencia solar. En otra fase la recopilación de la documentación necesaria para establecer los lazos históricos, tipológicos, iconológicos y geométricos, de esta manera la observación, análisis e interpretación, constituye el primer acercamiento en la identificación de este vitral distinguiendo tamaño, forma, iconografía y geometría que permita la rigurosidad en su reconocimiento patrimonial.

En este sentido es importante establecer que el conjunto de vitrales de la catedral corresponde a 60 unidades, adaptados a la arquitectura Neo renacentista, de la cual la Catedral de San José presenta su caracterización, según lo advertido por Vergel, Delgado \& Díaz (2019). En esta caracterización se pudo determinar la incorporación de escenas bíblicas, ángeles, santos, la imagen del sagrado corazón de Jesús, inmaculado corazón de María, Santísima Virgen Maria, San José y Jesús, como manifestación artística de la arquitectura sagrada.

A esta información se vincula un dato relevante, su autoría, puesto que se establece en la casa Mauméjean con orígenes en Europa de 1860 (Vergel, Delgado \& Díaz 2020), quienes afirman que: "Todas estas observaciones arquitectónicas se complementan, con el valor artístico ya que 
se revela la autoría con la vidriera Mauméjean, una de las fábricas de arte decorativo más importantes de Europa." (pag.123), calculando por las inscripciones identificadas, que la manufactura de este vitral muy probablemente se da hacia 1923 en Madrid, España (Sociedad Mauméjean 2.010) y que llegaron de forma expresa gracias a la apertura económica de San José de Cúcuta en aquella época (Vergel, Delgado \& Díaz 2020).

\section{ANÁLISIS}

En cuanto a su iconografía, se distingue, las representaciones del Espíritu Santo en la Iglesia asociadas con el bautismo del Señor; a la representación de la Santísima Trinidad; las que forman la escena de Pentecostés; $y$, por último, las que aparecen como símbolo de la concepción virginal de Santa María, (Íñiguez, 1998, pág. 559). En este sentido se puede identificar la paloma, tal como aparece en el bautismo de Jesucristo en el Jordán, descrito en los textos de San Mateo:" Bautizado Jesús, salió luego del agua; y he aquí que se abrieron los cielos, y vio al Espíritu de Dios descender como paloma y venir sobre él" (Mt. III, 16), San Marcos: "En el instante en que salía del agua vio los cielos abiertos y al Espíritu, como paloma, que descendía sobre Él (Mc. 1, 10) y San Lucas: "Aconteció, pues, cuando todo el pueblo se bautizaba que, bautizado Jesús y orando, se abrió el Cielo, y descendió el Espíritu Santo, como una paloma, sobre Él” (LC. I1I, 21-22).

Al mismo tiempo, el Espíritu Santo es dilucidado por lenguas de fuego. El día de Pentecostés, por ejemplo, se interpreta sobre la virgen Maria y los apóstoles reunidos en el cenáculo, descrita por San Lucas en los Hechos de los Apóstoles: Aparecieron, como divididas, lenguas de fuego que se posaron sobre cada uno de ellos, quedando todos llenos del Espíritu Santo (Le. 11, 3-4). De ahí, el Espíritu Santo aparece representado también como llamas de fuego (Íñiguez, 1998, Pág. 562). Se comprende de esta manera, la iconología de la paloma como un componente simbólico relacionado con mensaje que transmite la luz a través de los cristales de colores, como objeto ilustrativo en términos religiosos. En este sentido, Vallespin, Hernández \& Cervero (2015) refieren que el lenguaje simbólico de la luz con doble sentido, por un lado, como transmisión de la palabra de Dios a través de las imágenes luminosas dibujadas sobre las vidrieras y por otro, como concesión de la idea de la luz como representación de lo sagrado. De ahí se afirma el papel pedagógico y al mismo tiempo alegórico, donde prevalece la exaltación de la luz entendida como lo divino (Vergel, Delgado \& Díaz 2020).

Para comprender la importancia de este vitral en la simbología de la catedral de San Jose de Cúcuta se cita a Meis (1979,) quien afirma que el Espíritu Santo es considerado como de igual dignidad divina que el Padre y el Hijo. Este autor reflexiona que se resalta con más fuerza en 58,2 de la Carta de Clemente Romano, considerado como "preludio del Símbolo Apostólico" y en la Ascensión de Isaías 8,18, donde reza: "Todos juntos glorificaban al primer Padre de todos, al Bienamado, el Cristo y al Espíritu Santo". (Meis, 1979, pág. 227). Es revelador que la acción del Espíritu sobre la fe se conecta siempre con la Celebración Eucarística. Este autor, hace alusión a la tradición Apostólica, que se dirige al Padre para pedir "que tenga a bien enviar su Espíritu Santo sobre la población de la santa Iglesia, que une a todos los santos y conceda a los que reciben la población que sean llenos del Espíritu Santo para que él fortalezca su fe por la verdad" (pág. 230). De esta manera los creyentes pueden alabar al Padre por el Hijo. Es pues el Espíritu Santo quien posibilita que la alabanza de los fieles llegue al Padre por medio del Hijo. (Meis, 1979, pág. 230). (ver imagen 1) 
Imagen 1. Corte crucero y ábside, con ubicación del vitral del Espíritu Santo en relación al altar. Detalle grafico de la proyección lumínica hacia al altar a través del vitral.

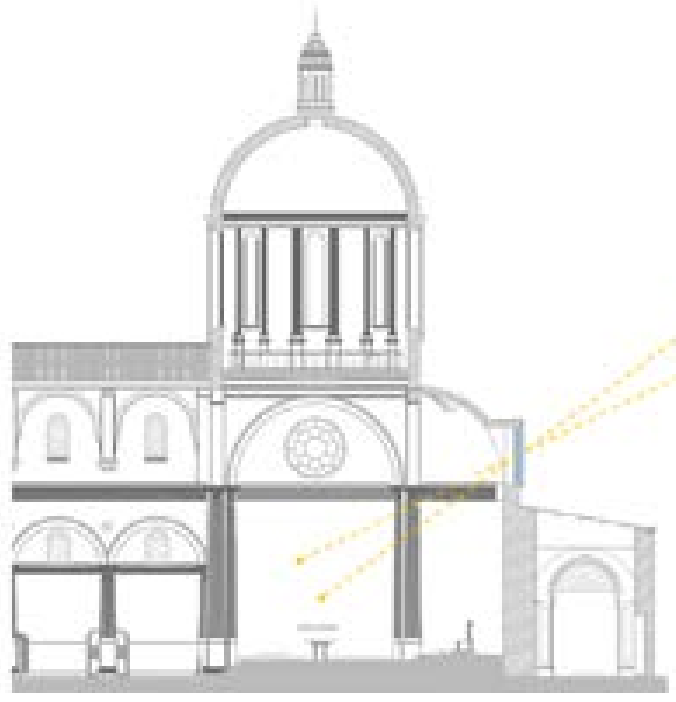

Fuente: propia.

Con esta descripción se da explicación a su estratégica ubicación en el ábside, muy próximo al altar, justo de frente a los feligreses en la celebración Eucarística. El vitral del Espíritu Santo esta en dirección al este, por lo que la asolación del naciente atraviesa toda la cristalera produciendo un bello efecto, cuanto más cercano a las horas de la mañana entre 8-00am y 10 am su visibilidad es radiante (ver imagen 2 ), Tal como lo relaciona Llambard( 1991), cuando refiere que "todos los templos cristianos que se han edificado siempre según un eje este-oeste (el llamado «eje litúrgico»), estando la cabecera a oriente y la fachada principal de acceso en el frente opuesto, a occidente."(pág. 15)

Imagen 2. Vista axonometría de la incidencia solar en la Catedral de San José, el 13 de agosto a las 8:00 am.

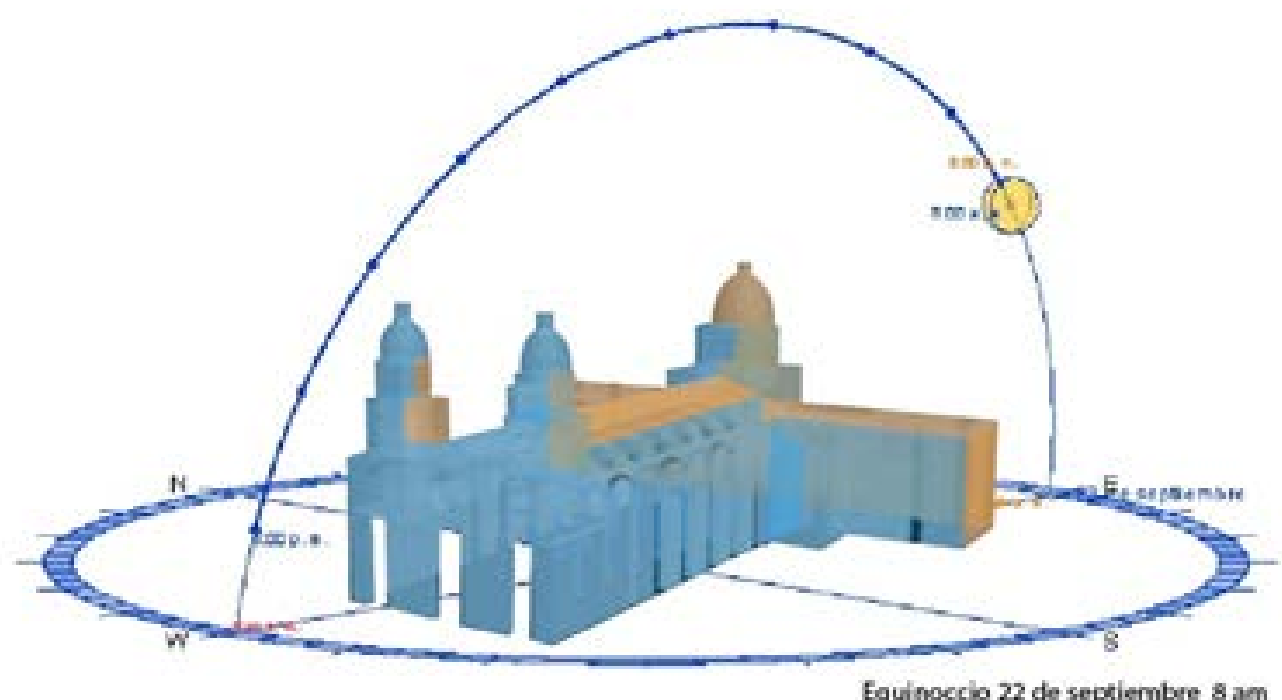

Fuente: Modelado Autodesk Revit, por Catherine Contreras. 
Esto quiere decir que, con la orientación en el eje litúrgico, es posible admirar los colores nítidos del rosetón, la paloma como el centro de la composición y las leguas de fuego en un esquema radial lograda con naranjas, amarillos y azules. En efecto, el vitral está orientado convenientemente a la luz matinal, de ahí el efecto tamizado y cromático baña el interior del altar, al presbítero y la consagración, fenómeno lumínico totalmente visible a los asistentes, tal como análogamente en el sentido icónico Santo Tomas de Aquino en Alpízar (2016) declara

\begin{abstract}
"También el Espíritu Santo apareció visiblemente, o en "figura de paloma" sobre cristo en el bautismo, o como en "lenguas de fuego" sobre los apóstoles, $\mathrm{Y}$ aunque no se hiciera paloma o fuegocomo el hijo se hizo hombre-no obstante, se dejó ver en tales apariencias como en imágenes de sí mismo, y así también él estuvo en el mundo de modo nuevo, ósea de modo visible. (pág. 9)
\end{abstract}

Algo semejante ocurre, con el referente a nivel mundial, del rosetón en vitral del Espíritu Santo, ubicado muy próximo al altar de Bernini en la Basílica de San Pedro del Vaticano, tan conocido y de relevancia especial dentro del amplio patrimonio arquitectónico y artístico de la Iglesia Católica (Réau 2000). Gaudiumpress (2018) afirma que la paloma de esta cristalera, tiene una distancia de las alas extendidas de $1.62 \mathrm{~m}$, desarrollado en arte vitral de manera artesanal entre 1656 y 1666. Su configuración de algún modo es análoga al vitral de la catedral, no solo por su iconografía sino también por la técnica aplicada.

No obstante, sus dimensiones son diferentes. En el caso del vitral de la catedral la envergadura de las alas de la paloma solo alcanza los $1.01 \mathrm{~m}$, por lo que el tamaño de vitral se puede calcular en el $62 \%$ del de la basílica. Así mismo los detalles cambian drásticamente al ser circunscritos en un círculo concéntrico, al contrario del sistema oval del modelo del Vaticano. De la misma forma, se anexa la paleta de colores de tonos azules y elementos decorativos que lo hacen autentica pieza de la casa Maumejean para el encargo de la catedral de San José de Cúcuta, con un estilo neoclásico. (ver Imagen 3)

Imagen 3. Imágenes fotográficas del vitral del Espíritu Santo la catedral de San Jose de Cúcuta y el vitral de la Basílica de San Pedro del Vaticano.
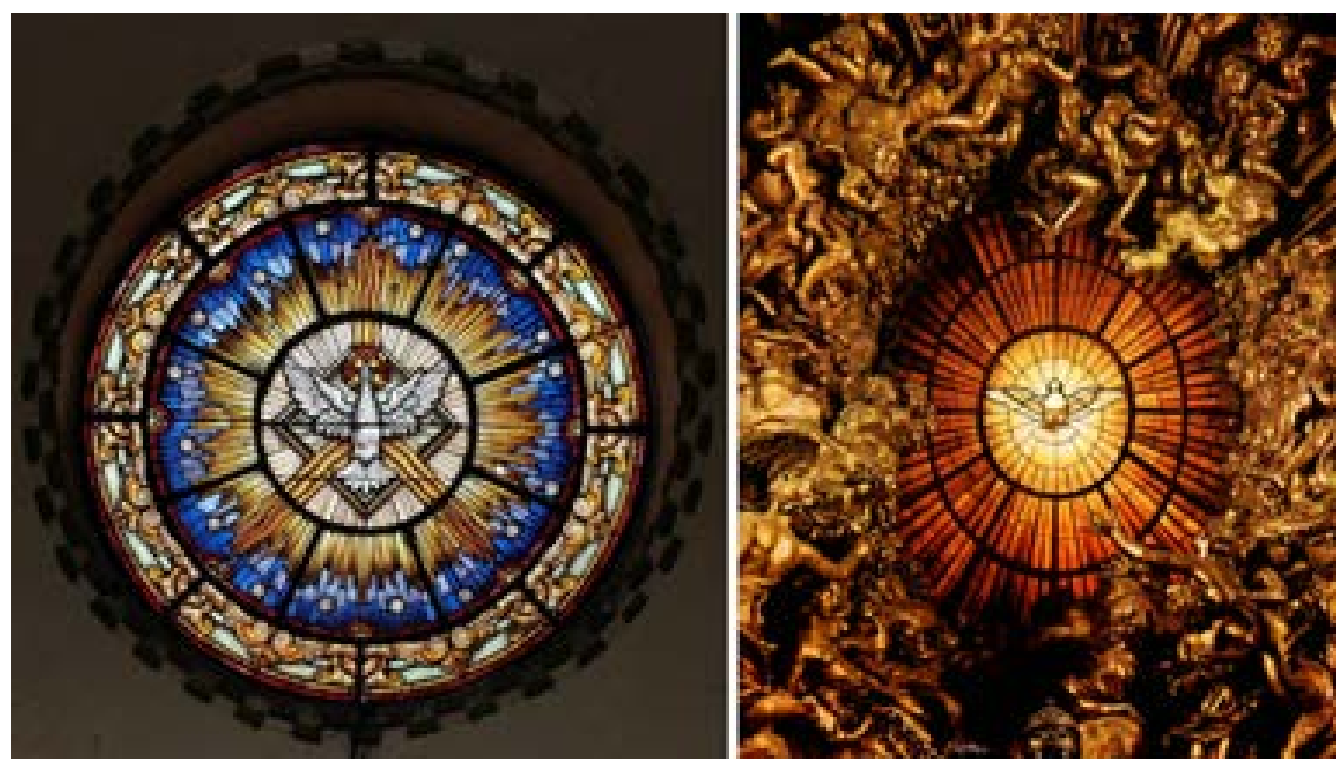

Fuente Propia e imagen https://www.pinterest.es/pin/68328119324977473/ 
En cuanto a la manufactura del vitral, se aprecia su tradicional sistema de vidrio pintado emplomado, según el procedimiento de cristales cortados de diversos tamaños y esmaltados, unidos por perfiles de plomo, soldados entre sí, masillados, y con barras de refuerzo. Toda esta estructura se inscribe en el medallón concéntrico central de 3,25 m de diámetro, regido por el icono de la paloma cuyas extremidades se disponen a través de un esquema radial $(50,7 \mathrm{~cm})$, que se ajusta al círculo central. La superficie de este primer círculo es de $1.02 \mathrm{~m} 2$, que corresponde al $16 \%$ del área total, y su soltura artística se da sobre el rombo, cuyos vértices tocan la periferia de este primer anillo.

No obstante, los segmentos circulares delimitados por la subdivisión horizontal de las cuatro barras de refuerzo estructural generan una tención contrapuesta al esquema radial que domina toda la composición. A partir del primer anillo de este círculo central, se desarrolla la siguiente corona circular con el entramado radial y estructural afín, conformado con los 592 fragmentos de vidrio en tonalidades amarillas y azules, remembrando la luz, las leguas de fuego y el cielo. Esta corona circular intermedia cuenta con un área de $2.64 \mathrm{~m} 2$ conformado por 8 piezas con forma de trapecio circular de 0,33 $\mathrm{m} 2$ cada uno alineados con un ángulo central de $45^{\circ}$. La última corona circular perimetral que da continuidad a la radialidad central, se calcula sobre 8 piezas de $0.33 \mathrm{~m} 2$ para un total de 2.64 $\mathrm{m} 2$ también a $45^{\circ}$ con orlas ubicadas en todo el perímetro. De esta forma se demuestra en el $84 \%$ del rosetón una dependencia geométrica por su composición simétrica radial en sus coronas circulares alrededor de la pieza vitral central del Espíritu Santo.

En coherencia con estas afirmaciones, Ccalli (2014), explica que si una obra artística, "está estructurada entorno varios ejes que parten de un punto situado en el centro geométrico de la composición, como si fueran los radios de una rueda" (pág. 24) el esquema es denominado simetría radial. Por consiguiente, la simetría radial es lograda no solo por la estricta geometría, vista en la estructura de las barras de refuerzo y los emplomados, sino también por el elemento central iconográfico del Espíritu Santo y las figuras aisladas circundantes con guardas de motivos figurativos. (ver imagen 4)

Imagen 4. Análisis Geométrico del Vitral del espíritu Santo de la Catedral de San José de Cúcuta.

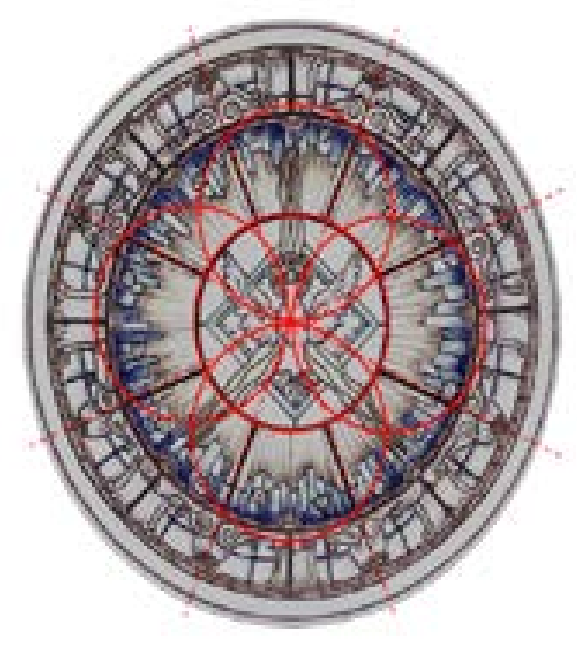

Fuente: Despiece de vitral a mano alzada de Manuela Chávez Díaz.

Retomando la composición central, e identificando el polígono regular inscrito de 4 lados y ángulos iguales ángulos iguales, que se dibuja enmarcando la paloma, y la disposición de alas y cola en esta misma forma radial, López (2014) afirma que este polígono se puede inscribir en una circunferencia, tal como sucede en este vitral, donde el icono del Espíritu Santo y las leguas de fuego se despliegan (Diaz, Vergel, Delgado, 2021). Justo en el centro de esta iconografía, se halla el centro del polígono, geométricamente localizado en el pecho de la paloma. De ahí, se dice que este marco, mencionado como el polígono se puede denominar el "cuadrilátero cíclico ó inscriptible." Al inscribirse en la circunferencia, a su vez se 
llama radio del polígono al segmento que une el centro del polígono con cualquier vértice, y apotema del polígono, al segmento que une el centro de la circunferencia circunscrita, con el punto medio de cualquier lado. (López, 2014 pág. 10 y 13)

También es de referenciar a toda luz que nada de lo propuesto constructivamente y ornamentalmente se da al azar, todo corresponde a una armonía y simbología universal. Por ejemplo, las formas y los números tienen una simbología mística, el circulo es cielo y el cuadrado tierra. En este caso, se inicia en el centro con 4 fracciones paralelas o segmentos circulares, el numero 4 simboliza plenitud y se relaciona con los cuatro puntos cardinales. El número 8 da lugar a las divisiones en la corona circular conformada por trapecios circulares a 4 . $5^{\circ}$, visto en 4 y $5,4+5=9$, asociado con la sabiduría, e identificado con el número de Dios. Con todo, se puede estimar que el arte del trazado en la construcción de cada uno de estos detalles, era una especialidad de las construcciones de catedrales, lograda con el uso de la regla y el compás, que permitía encontrar el esquema excepcional que reflejaba las leyes universales de la tierra y el cielo.

\section{CONCLUSIÓN}

Como resultado del estudio, se tiene que el rosetón del Espíritu Santo corresponde al juego de vitrales pedido especialmente a la casa Mauméjean, una de las fábricas de arte decorativo más importantes de Europa, para este caso, la sucursal establecida en Madrid, España, tal como parece en la epigrafía de cada una de las piezas que dotaron a este edificio Sagrado, con fecha de 1923.

Del mismo modo se distingue que el Espíritu Santo es considerado como de igual dignidad divina que el Padre y el Hijo, siendo indispensable en la tradición Apostólica, pues es quien posibilita que la alabanza de los fieles llegue al
Padre por medio del Hijo y la consagración. En este sentido se da explicación a su localización en el ábside de la catedral, mirando al este y privilegiando la entrada del sol entre 8:00am y 10:00 am, como estrategia lumínica directa al altar y visible al feligrés.

Se asocian las representaciones del Espíritu Santo en la Iglesia con el bautismo del Señor y las que forman la escena de Pentecostés; de ahí es identificado en el arte religioso por la paloma y las lenguas de fuego, tal como aparecen descritas en las citas bíblicas de San Lucas, San Marcos, San mateo y en los Hechos de los Apóstoles. Este componente simbólico corresponde con el mensaje que transmite la luz a través de los cristales de colores, como efecto fenomenológico.

En el estudio también, se referencia a nivel mundial, el vitral del Espíritu Santo, en la Basílica de San Pedro del Vaticano, reconocido en el amplio patrimonio artístico y arquitectónico de la Iglesia Católica. Este rosetón, tiene igualmente una paloma cuyas alas dimensionan la envergadura de $1.62 \mathrm{~m}$, elaborado de manera artesanal entre hacia 1666, con una estructura oval. En el caso del Espíritu Santo de la Catedral, $62 \%$ más pequeño, pues en contraste, la paloma posee amplitud de sus alas de $1.01 \mathrm{~m}$. En cuanto a los detalles, cambian drásticamente al ser circunscritos en un círculo concéntrico, y una paleta de colores de tonos azules con elementos decorativos que lo hacen legítimo de la casa Mauméjean.

Toda esta estructura en medallón concéntrico central de $3,25 \mathrm{~m}$, de diámetro, regido por el icono de la paloma cuya disposición en un esquema de simetría radial, desde el primer anillo concéntrico de $1.02 \mathrm{~m}^{2}$, el secundario de. $2.4 \mathrm{~m}^{2}$ y la última corona circular de $2.8 \mathrm{~m}^{2}$ con orlas ubicadas en todo el perímetro se organiza estrictamente de forma radial. En el centro del rosetón la composición se complejiza pues se observa un polígono inscrito en la circunferencia 
del primer anillo donde el icono del Espíritu Santo y las leguas de fuego se despliegan. De ahí, se identifica también "cuadrilátero cíclico ó inscriptible" desplegando una dependencia geométrica radial en un $84 \%$ para la composición artística e iconográfica del vitral del Espíritu Santo.

\section{REFERENCIAS BIBLIOGRÁFICAS}

Alpízar, Nelson (2016). Estudio para una representación gráfica del espíritu santo según la Biblia, mediante técnicas de grabado experimental. Proyecto de Grado, Licenciaturas en artes, Universidad de Costa Rica. Visto en : $\quad$ http://repositorio.sibdi.ucr.ac.cr:8080/jspui/ bitstream/123456789/3526/1/40489.pdf

Campo, B. (1998). La idea construida la arquitectura a la luz de las palabras. Textos Dispersos Colegio Oficial de arquitectos de Madrid (coam). España.

Ccalli, Juan (2014). Análisis Técnico de las obras del círculo pictórico Laykakota de la ciudad de Puno entre los años 1933-1940. Visto en: http:// repositorio.unap.edu.pe/handle/UNAP/9762

Delgado, A., Díaz, Y. \& Vergel, M. (2.018). El paisaje Arquitectónico y sonoro del campanario de la Catedral de San José de Cúcuta. Revista Logos Ciencia \& Tecnología.vol.11 N 1, enero marzo 2.019 P52-60v

Díaz Umaña, Y., Delgado Rojas, J. A., \& Vergel Ortega, M. (2021). Representaciones socioespaciales, en la memoria histórica de la catedral y su entorno urbano en San José de Cúcuta. Revista Boletín Redipe, 10(4), 376-387. https://doi.org/10.36260/rbr.v10i4.1277

Díaz Umaña, Y., Delgado Rojas, J. A., \& Vergel Ortega, M. (2021). El espíritu de la luz. Bogotá: Ecoe ediciones

Díaz, Y. (2019). La arquitectura sagrada en San José de Cúcuta (I Parte): Caso de estudio, Iglesia de Nuestra Señora de la Candelaria. Trabajo investigativo presentado para el escalafón docente. UFPS, Cúcuta, Colombia.

Delgado, J. (2020). Modelo geométrico y arquitectónico de la cúpula mayor en San José de Cúcuta. Revista boletín Redipe 9 (3):160-166 marzo 2020 [En línea]: https:// www.researchgate.net/publication/340362293 Modelo_geometrico_y_arquitectonico_de_ la_cupula_mayor_en_San_Jose_de_Cucuta Vergel, $\mathrm{M}$;

Delgado, J \& Díaz, Y. (2019). Cathedral bell's San José de Cúcuta: Heritage and acoustics. XIV Applied Mathematics Meeting and XI Statistics Meeting, IOP Conf. Series: Journal of Physics: Conf. Series 1329 (2019) visto en: https://iopscience.iop.org/ article/10.1088/1742-6596/1329/1/012004/pdf

Gaudiumpress (2018). Pintando con luz: Una mirada al estudio artístico que ha producido algunos de los más célebres vitrales del Vaticano. Roma, 18-05-2018, Gaudium Press. Visto en: https://es.gaudiumpress.org/ content/95308-pintando-con-luz-una-mirada-alestudio-artistico-que-ha-producido-algunos-delos-mas-celebres-vitrales-del-vaticano/

İñiguez, Jose Antonio (1998). La iconografía del Espíritu Santo. SCRIPTA THEOLOGICA 30 (1998/2) 559-586. Visto en : file:///C:/Users/ufps/ Downloads/ST_XXX-2_10.pdf

Llambard, Ramón (1991). Catedral de Santa María de Urgel. Bien de Interés Cultural Visto en: https://www.arauacustica.com/files/noticias/ pdf_esp_1314.pdf

López, Roció (2014). PROBLEMAS SOBRE CUADRILÁTEROS. Trabajo de grado. Universidad de Granada. Visto en: https://www. ugr.es/ anillos/textos/pdf/2014/Geometria4.pdf 
Meis, Anneliese (1979). El Espíritu Santo en la confesión de fe del siglo II. Revista "iglesia de Santiago" "lecllo inaugura lis" de la Facultad de Teología. Visto en : https://repositorio.uc.cl/xmlui/ bitstream/handle/11534/15075/000406277.pdf

Panofsky, Erwin (1970). Estudios sobre iconología, Bs. As. Alianza Editorial Introducción, cap. I, p. 25.

El significado de las artes visuales, Bs. As., Infinito, 1970, p. 42.

Réau, Louis (2000), Iconografía del arte cristiano. Introducción General. Serbal, Barcelona, pp. 211-229 [ $1^{\text {a }}$ ed: Presses Universitaires, Paris, 1955].

Sociedad Mauméjean (2.010). Casa Mauméjean de vidrieras artísticas. Pag.web empresarial visto en: http://www.vidrierasmaumejean.com/ es-vidrieras-maumejean-s-I-clientes.html

Vallespin, A., Hernández, L. \& Cervero, N. (2.015). El espacio Gótico según Hans Jantzen y la evolución de las vidrieras. Universidad Politécnica de Valencia. Visto en: https://doi. org/10.4995/ega.2015.3671

Vergel Ortega, M.., Delgado Rojas, J. A.., \& Díaz Umaña, Y. (2020). Estudio iconográfico y geométrico del vitral de San José en la catedral de Cúcuta. Revista Boletín Redipe, 9(6), 119133. https://doi.org/10.36260/rbr.v9i6.1006

Vergel Ortega, M., Delgado Rojas, J. A. \& Díaz Umaña, Y. (2020). Dimensión histórica de la red ferroviaria, su impacto económico y urbano en San José de Cúcuta. Revista Boletín Redipe, 9(6), 183-191. https://doi.org/10.36260/rbr. v9i6.1011 